\title{
Computer understanding of natural language
}

\author{
ROGER C. SCHANK \\ Department of Computer Science, Yale University, New Haven, Connecticut 06505
}

The state of research in automatic natural language processing at Yale University is described. Five programs are discussed: SAM, FRUMP, PAM, TALESPIN, and POLITICS.

This paper discusses the state of research in automatic natural language processing at Yale University as embodied in the particular computer programs that we have developed; but not all projects are included. For each program, an introduction to its overall intent is given. After the input/output for that program has been presented, a short discussion of the research underlying that program is given, together with a prognosis for the future development of the program.

The programs discussed are: (1) SAM-a script-based story understanding program. SAM is intended to model a human story understander reading a story about which he has detailed knowledge that will reliably help him to understand. (2) FRUMP-a fast program designed to skim a newspaper looking for events in which it is interested. FRUMP is based on what we call "sketchy scripts." (3) PAM-a plan-based program designed to understand stories that call upon general knowledge of human goals and relationships rather than the detailed script world of SAM. (4) TALESPIN-a program that makes up stories to tell in an interactive mode. TALESPIN uses plans and goals to determine how events relate in the world it is describing. (5) POLITICS-a program designed to read newspaper headlines and simulate a person with an ideological belief system being informed of the events in the headlines. The program is then capable of answering questions based on its belief system about appropriate responses of the U.S. to the news events.

\section{BACKGROUND}

For many years, work on computer processing of natural language was primarily concerned with the syntactic analysis of sentences. This work was done with the initial intention of being useful in automatic translation efforts, but the work eventually ended, partially because of the shortsightedness of researchers who thought that they could do translation without recourse to meaning analysis. Later efforts in computational linguistics continued to stress problems of

This work is supported in part by the Advanced Research Projects Agency of the Department of Defense and monitored under the Office of Naval Research under Contract N00014-75-C-1111. syntactic analysis. Many parsers were written without regard to the eventual use of such programs.

Work in the area of artificial intelligence began to focus on the issue of why and how language need be treated by computer programs. Many artificial intelligence (AI) programs could use, or absolutely required, front ends that processed natural language. But, in all of these cases, what was required were programs that handled the meaning of sentences rather than their syntactic parse trees. Work did not proceed directly on the creation of such programs because: (1) researchers naturally assumed that any meaning analysis procedure would work on top of, or after, a syntactic analysis procedure; and, (2) no well defined meaning representation existed. It was thus impossible to talk about mapping sentences into meanings when it was barely understood what meanings were.

For the past 10 years, my colleagues and I have been working on a meaning representation theory. Our goal was to have a meaning representation that would be useful as the basis of computer programs using information about the outside world, whether expressed originally in language or not. It was our intent that this meaning representation be able to effectively guide the meaning analysis process by predicting what information was missing that would help tie things together.

Since the meaning representation output by our analyzer was to be used by a memory model, we quickly became concerned with the problem of limiting the enormous potential size of the inference data and processes. Accordingly, we required of our meaning representation that it be unambiguous, unique, and language free. These requirements essentially meant that any two inputs, whether in the same or different languages, no matter how constructed with respect to word choice or syntactic form, would have only one possible meaning representation if they had the same meaning.

Recently, we began to work on the problems of tying text together and building a program that would understand stories. In attempting to solve these problems, we invented the idea of a script. A script is a preformed sequence of actions that constitute the natural order of a piece of knowledge. For example, consider the sequence, "John went to a restaurant. 
He found a table and ordered a hamburger. Later, he paid and left." Unless we have detailed knowledge about restaurants (the restaurant script), we cannot easily connect finding tables and ordering. Nor can we consider the question, "What did John eat?" However, any person who knows about restaurants can do these things. Scripts, then, serve to fill in the gaps in a causal chain when they cannot be inferred just by themselves. That is, scripts form the knowledge source that we rely on in understanding. [Although the ideas were developed independently, scripts conform well to one part of Minsky's (Note 1) frame idea.]

We built a program (SAM) that understands stories about domains about which it has knowledge. We started with restaurant stories. With respect to our objectives, scripts obviated the problems of the length of stories. Thus, SAM is capable of understanding stories of any length as long as they deal with scripts.

\section{THE PROGRAMS}

\section{SAM}

The SAM program works by analyzing each sentence into a conceptual dependency representation. This representation invokes a script (a script is brought into memory). Future inputs are analyzed and then matched against the script. If a new input matches, any necessary steps that are known to have been skipped between the first input and the second are inferred to have happened. This continues until there are no new inputs or until a new input does not match a part of the current script.

After completing the analysis of the story into a causally connected chain of conceptual dependencies, we pass that chain to a paraphrase progran or a summary program. These programs have measures of the importance of an item in a script and create as output the conceptual dependencies that they deem most important. This output is then passed to the generator, which maps what it receives from the paraphraser or summarizer into English.

We can also translate the input stories into a variety of languages, as well as answer questions about the stories. Story 1 below relies on multiple knowledge bases (called scripts), as well as having a complication arise in one script as a result of an odd occurrence in a previous one. Story 2 is an actual newspaper story that SAM has processed.

SAM understands these stories and others like them. By "understand," we mean SAM can create a linked causal chain of conceptualizations that represent what took place in each story. SAM parses the story into input conceptualizations using Riesbeck's (1975) analyzer. These are then fed to a program that looks for script applicability (Cullingford, 1977). When a script seems to be applicable, it is used by the script applier to make inferences about events that must have occurred between events specifically mentioned.
The final internal representation is a language-free network of concepts and their interrelations. SAM generates paraphrases that are longer than the original (this is possible since inferences made by the script applier are retained). We also generate paraphrases that are shorter and closer to the original and summaries that rely on measures of the relative importance of events within a script. In addition, we have developed a program that can query the obtained representation so as to answer questions about the input story (see Lehnert, 1977).

Since the representation language that we use (conceptual dependency; see Schank, 1975) is intended to be interlingual, generation in English is no harder for us than generation in any other language. Thus, we have also written generation programs that translate the stories we understand into Chinese, Russian, Dutch, and Spanish. The translation programs work by taking the output from the script applier and encoding it according to the rules of the target language.

\section{Below is Story 1.}

Story 1. John went to New York by bus. On the bus he talked to an old lady. When he left the bus, he thanked the driver. He took the subway to Leone's. On the subway his pocket was picked. He got off the train and entered Leone's. He had some lasagna. When the check came, he discovered he couldn't pay. The management told him he would have to wash dishes. When he left, he caught a bus to New Haven.

Long paraphrase. JOHN WENT TO A BUS STOP. HE WAITED AT IT A FEW MINUTES. HE ENTERED A BUS. THE DRIVER GOT THE TICKET FROM JOHN. HE WENT TO A SEAT. HE SAT DOWN IN IT. WHILE JOHN WAS ON THE BUS AN OLD LADY AND JOHN TALKED. THE DRIVER TOOK JOHN TO NEW YORK. HE WENT TO THE DRIVER. WHEN GETTING OFF THE BUS JOHN THANKED THE DRIVER. JOHN GOT OFF IT.

HE ENTERED A STATION. HE PUT A TOKEN INTO THE TURNSTILE. HE WENT TO THE PLATFORM. HE WAITED AT IT A FEW MINUTES. HE ENTERED A SUBWAY CAR. A THIEF WENT TO JOHN. THE THIEF PICKED JOHN'S POCKET. HE WENT. JOHN WENT TO THE SEAT. HE SAT DOWN IN IT. THE DRIVER TOOK JOHN TO LEONE'S. HE LEFT THE SUBWAY CAR. HE LEFT THE STATION.

HE ENTERED LEONE'S. HE LOOKED AROUND INSIDE IT. HE SAW HE COULD GO TO A TABLE. HE WENT TO IT. HE SAT DOWN IN THE SEAT. HE ORDERED SOME LASAGNA. THE WAITER INDICATED TO THE CHEF JOHN WOULD LIKE HIM TO PREPARE SOMETHING. THE CHEF PREPARED THE LASAGNA. THE WAITER GOT IT FROM THE CHEF. THE WAITER WENT TO THE TABLE. HE SERVED THE LASAGNA TO JOHN. HE BECAME FULL.

HE ASKED THE WAITER FOR THE CHECK. JOHN GOT IT FROM THE WAITER. JOHN DISCOVERED HE WAS UNABLE TO PAY THE CHECK. HE INDICATED TO THE WAITER HE WAS UNABLE TO PAY THE CHECK. THE MANAGEMENT TOLD JOHN HE WOULD HAVE TO WASH DISHES. HE ENTERED THE KITCHEN. HE WASHED THE DISHES. HE LEFT LEONE'S.

HE WENT TO THE BUS STOP. HE WAITED AT IT A FEW MINUTES. HE ENTERED THE BUS. THE DRIVER GOT THE TICKET FROM JOHN. HE WENT TO THE SEAT. HE SAT DOWN IN IT. THE DRIVER TOOK JOHN TO NEW HAVEN. HE GOT OFF THE BUS. [Paragraphing has been added to the computer output for ease of reading.]

Short paraphrase. JOHN TOOK A BUS TO NEW YORK. 
HE TOOK THE SUBWAY TO LEONE'S. ON THE SUBWAY A THIEF PICKED JOHN'S POCKET. JOHN ENTERED LEONE'S. HE ORDERED SOME LASAGNA. HE ATE IT. HE DISCOVERED HE WAS UNABLE TO PAY THE CHECK. THE MANAGEMENT TOLD JOHN HE WOULD HAVE TO WASH DISHES.

Below are questions asked to SAM (in English), which have been answered by SAM'.

Q1: Why did John go to New York?

A1: BECAUSE JOHN WANTED TO GO TO LEONE'S.

Q2: How did John get to Leone's?

A1: JOHN TOOK A BUS TO NEW YORK AND THEN HE

TOOK THE SUBWAY TO LEONE'S.

Q3: Did anything unusual happen on the bus?

A 3: I DON'T REMEMBER ANYTHING.

Q4: Did anything unusual happen on the subway?

A4: A THIEF PICKED JOHN'S POCKET.

Q5: What did John order?

A5: JOHN ORDERED LASAGNA.

Q6: Did anything unusual happen at the restaurant?

A6: JOHN DISCOVERED THAT HE COULDN'T PAY THE CHECK AND SO HE HAD TO WASH DISHES.

Q7: Why couldn't John pay the check?

A7: BECAUSE JOHN DID NOT HAVE ANY MONEY.

Q8: Why didn't John have any money?

A8: BECAUSE A THIEF PICKED JOHN'S POCKET.

Q9: How did John get back to New Haven?

A9: JOHN WENT FROM LEONE'S BY SUBWAY AND THEN HE WENT TO NEW HAVEN BY BUS.

Q10: How was John able to take the bus to New Haven? A 10: PROBABLY JOHN HAD A TICKET.

Below is the Chinese translation of Story 1 produced by SAM.

John tzuoh charng twu chih che daw Neou Iue chiuh le. Ta tzay charng twu chi che lii. Ta gen i wey lao tay tay tarn i tarn. Ta tsorng charng twu chih che lii chiuh chuh le. Ta shieh shieh sy ji. Ta tzuoh dih shiah huoo che daw Leone's chiuh le. Ta tzay dih shiah tiee luh che lii. I ge par shoou tou le chyan. Ta tasorng dih shiah tiee luh che chuh chiuh le. Ta jinn le Leone's. Ta chr le i da li tsay. Ta tsorng char farng nadaw i ge jang dhan. Ta fa shyann ta bu kee yii fu chyan. Char farng jiaw ta bih shiu yaw shii bei tz. Ta tsorng fang guar lii chu chiuh le. Ta tzuoh charng tu chi che daw Shin Gang chiuh le.

Story 2 was obtained from the New Haven Register.

Story 2. A New Jersey man was killed Friday evening when the car in which he was riding swerved off Route 69 and struck a tree. David Hall, 27, was pronounced dead at the scene by Dr. Dana Blauchard, medical examiner. Frank Miller, 16, of 593 Foxon Road, operator of the vehicle, was taken by Flanagan Ambulance to Yale-New Haven Hospital. He was treated and released. The Branford Fire Department extricated the passenger from the vehicle. No charges were made. Patrolman Robert Onofrio is continuing the investigation.

Question-Answering Output

Q1: Was anyone killed?

A1: YES, DAVID HALL DIED.

Q2: Was anyone hurt?

A2: YES, FRANK MILLER WAS SLIGHTLY INJURED.

Q3: Why was Frank Miller hurt?

A3: BECAUSE THE AUTOMOBILE HIT A TREE.

Q4: Did Frank Miller go to the hospital?

A4: YES, HE WAS IN YALE-NEW HAVEN.
Q5: How did Frank Miller get to the hospital?

A5: AN AMBULANCE TOOK HIM TO YALENEW HAVEN.

Summary. AN AUTOMOBILE HIT A TREE NEAR HIGHWAY 69 FOUR DAYS AGO. DAVID HALL, AGE 27, RESIDENCE IN NEW JERSEY, THE PASSENGER, DIED. FRANK MILLER, AGE 16 RESIDENCE AT 593 FOXON ROAD IN NEW HAVEN, CONNECTICUT, THE DRIVER, WAS SLIGHTLY INJURED. THE POLICE DEPARTMENT DID NOT FILE CHARGES.

\section{FRUMP}

Another newspaper story reading program operating at Yale is FRUMP (fast reading and understanding memory program). FRUMP is a program intended to skim a newspaper quickly while looking for things it is interested in. FRUMP uses simpler, less detailed scripts than SAM. Furthermore, its parsing is done directly from the scripts. After a story has been identified to be relevant to a domain of interest, the particular items that are interesting to FRUMP in that domain are predicted. Special-purpose expectations are set up to look for the concepts around which FRUMP'S expectations are organized. Sentences are never completely parsed. When a relevant concept is found, rules of English are used to find the information that FRUMP wants to know.

FRUMP is a very fast program compared to SAM. While SAM often takes a few minutes of CPU time to read a long story, FRUMP rarely takes more than a few seconds to read the same story. SAM is set up to understand a domain fully enough so that it can detect problems or unusual circumstances and understand the kinds of complications that can arise in a story (as it did in Story 1). However, for very static newspaper stories describing ordinary events, we have come to believe that the full power of SAM is a hindrance at times. FRUMP can do no more than skim a newspaper story about which it has knowledge, but it is very fast at what it does.

We have hooked FRUMP up to the UPI news wire, and FRUMP now reads stories directly from the wire. It is capable of informing a user who is currently logged in of stories in which he has expressed a general interest by sending him a summary of the story (in a choice of different languages) as soon as it comes across the wire. (This program is described in more detail by DeJong, Note 2.) Below are some stories that came across the UPI wire recently that were read by FRUMP.

Input. --UPI 7 -11 11:32 AED----A104 D I SS CZC U V PM-BUS 7 -11-_-_- - - - MOSCOW (UPI)-FIFTEEN SOLDIERS WERE KILLED AND MANY OTHERS INJURED THIS WEEKEND WHEN AN ARMY TRUCK COLLIDED WITH A BUS OUTSIDE MOSCOW, WESTERN DIPLOMATIC SOURCES SAID TODAY. THE SOURCES SAID THEY HAPPENED ON THE WRECK SUNDAY WHILE DRIVING ON THE ROAD FROM MOSCOW TO THE CITY OF VLADIMIR. SOVIETS AT THE SCENE TOLD THE DIPLOMATS 15 PERSONS HAD DIED IN THE CRASH AND MANY MORE WERE INJURED. THEY SAID THE ARMY 
TRUCK WAS DESTROYED AND THE BUS HEAVILY DAMAGED. TRAFFIC ON THE ROAD WAS STOPPED FOR THREE HOURS, THEY SAID. ----UPI 7 -11 $11: 34$ AED

CPU TIME $=18.976$ SECONDS

ENGLISH SUMMARY:

A TRUCK CRASH CLAIMED 15 LIVES AND INJURED MANY IN MOSCOW.

- - - -UPI 10 -8 3:53 PED_-_-*** A241 D I SS BYL U V AM-FLOODS $10-8-\ldots \ldots$ NEW DOWNPOURS HIT FLOOD-RAVAGED AREAS OF NORTHERN ITALY SATURDAY, TURNING GENOA STREETS INTO RIVERS, CUTTING OFF THE ALPINE CITY OF AOSTA AND SWELLING TRIBUTARIES OF THE MIGHTY RIVER PO.

THE DROWNING DEATHS OF THREE MEN NEAR ASTI, NEAR ALESSANDRIA AND AT ISELLE RAISED THE KNOWN DEATH TOLL IN THREE DAYS OF FLOODING TO 12, WITH MANY MORE REPORTED MISSING.

POLICE SAID THEY FEARED A NUMBER OF MOTORISTS MAY HAVE DIED IN CARS SWEPT AWAY BY RAMPAGING STREAMS IN THE MOUNTAINS BETWEEN TURIN AND GENOA.

THE GENOA FIRE BRIGADE REPORTED STREETS, STORES AND APARTMENTS FLOODED, POLICEWOMEN JOINED FIREMEN IN RESCUING CHILDREN AND TEACHERS TRAPPED BY FLOODWATERS IN A NURSERY SCHOOL

LIGHTNING HIT AN EMPTY STORAGE TANK IN A GENOA REFINERY FRIDAY NIGHT, IGNITING OIL FUMES. FIREMEN FOUGHT ALL NIGHT TO PREVENT THE FIRE FROM SPREADING TO OTHER TANKS.

THE DORA BALTEA RIVER OVERFLOWED, CUTTING OFF THE CITY OF AOSTA IN THE ALPS NEAR THE FRENCH BORDER AND FLOODING A CHOCOLATE FACTORY AND AN ENGINEERING PLANT.

$$
\text { -UPI } 10 \text {-8 3:57 PED }
$$

CPU TIME $=22.835$ SECONDS

ENGLISH SUMMARY:

3 PEOPLE WERE KILLED WHEN A RIVER OVERFLOWED IN ITALY.

NS - -***A228 R W SS BYL BYL RYR

AM-SALT SKED 9 -22 DANILOFF-WASHINGTON (UPI)-THE UNITED STATES WELCOMED SOVIET FOREIGN MINISTER ANDREI GROMYKO THURSDAY WITH A STATEMENT IT WILL CONTINUE TO ABIDE BY THE EXPIRING STRATEGIC ARMS ACCORD SO LONG AS RUSSIA ALSO OBSERVES ITS PROVISIONS.

THE ADMINISTRATION TOLD CONGRESS IN A LETTER IT WILL ISSUE A "UNILATERAL STATEMENT" PLEDGING THE UNITED STATES TO OBSERVE THE 1972 SALT I AGREEMENT EVEN AFTER ITS OCT. 3 EXPIRY DATE.

THE DECISION WAS CONVEYED TO SEN. JOHN SPARKMAN, D-ALA., CHAIRMAN OF THE SENATE FOREIGN RELATIONS COMMITTEE, DIPLOMATIC SOURCES SAID. IT SPARKED IMMEDIATE CONCERN AMONG SOME SENATORS, INCLUDING SEN. HENRY JACKSON, D-WASH.

AT THE STATE DEPARTMENT, SECRETARY OF STATE CYRUS VANCE BEGAN A FIRST ROUND OF TALKS WITH GROMYKO IN AN EFFORT TO BREAK THE CURRENT STALEMATE IN $U$. S. SOVIET STRATEGIC ARMS LIMITATION TALKS AND OPEN THE WAY TO A NEW ACCORD.

GROMYKO WAS SCHEDULED TO MEET PRESIDENT CARTER FRIDAY. THE SOVIET OFFICIAL SAID ON ARRIVAL WEDNESDAY PROGRESS WOULD REQUIRE
MOVEMENT BY BOTH SIDES. BUT U. S. OFFICIALS SAID THEY ANTICIPATED NO MAJOR SOVIET CONCESSIONS CPU TIME $=17.290$ SECONDS

ENGLISH SUMMARY:

CYRUS VANCE MET WITH ANDREI GROMYKO IN THE UNITED STATES ABOUT THE SALT AGREEMENT.

-----UPI 8 -2 12:11 PED----***A2 I R I SS BYLCZC PM-SAFRICA 1 STLD-PICKUP3RDGRAF A040 8 -4 - -BY ERIK VAN EES ---JOHANNESBURG, SOUTH AFRICA (UPI)-RIOT POLICE FIRED BIRDSHOT TODAY AT CROWDS OF BLACKS THROWING STONES AT POLICE CARS AND OTHER VEHICLES IN THE GHETTO OF SOWETO. NO CASUALTIES WERE REPORTED.

BRIG. JAN GERBER, DEPUTY POLICE CHIEF FOR THE RESTIVE BLACK SUBURB ON THE OUTSKIRTS OF JOHANNESBURG, SAID 25 BLACKS, INCLUDING 10 FEMALES, WERE ARRESTED.

GERBER CHARACTERIZED THE SITUATION TODAY AS RELATIVELY CALM AND SAID ICY WINDS THAT DROPPED THE TEMPERATURE TO 34 DEGREES WERE PARTLY RESPONSIBLE.

THE "TROUBLEMAKERS WAIT FOR THE SUN TO WARM THEM UP BEFORE THEY GO INTO ACTION," HE SAID

CPU TIME $=12.556$ SECONDS

ENGLISH SUMMARY:

THERE WAS FIGHTING BETWEEN POLICE AND BLACKS IN SOWETO, SOUTH AFRICA. NO ONE WAS REPORTED INJURED.

\section{PAM}

Not all stories are based on scripts. Thus more general and more powerful mechanisms are sometimes necessary in order to understand a story. PAM (plan applier mechanism) is a program running at Yale that is intended to understand more general plan-based stories. It is described by Schank and Abelson (1977) and by Wilensky (1976).

A plan-based story is one in which the central characters must develop fairly novel plans to deal with problems and interferences that have occurred with respect to goals that they are interested in attaining. Truly interesting stories are plan based rather than script based.

Over the past 2 years, we have been developing a theory of how people understand such complex stories (see Schank \& Abelson, 1977). PAM was an early test of some of those theories. PAM uses knowledge about goals, themes, and plan boxes to figure out the intentions of all the characters it hears about. The program's job is to keep track of the goals of each of the characters in a story and to interpret their actions as means of achieving those goals. Below is Story 5, followed by the output PAM produces after processing it.

Story 5. (1) JOHN WANTED SOME MONEY. (2) JOHN GOT A GUN. (3) AND WALKED INTO A LIQUOR STORE. (4) JOHN TOLD THE OWNER HE WANTED SOME MONEY. (5) THE OWNER GAVE JOHN THE MONEY. (6) AND JOHN LEFT.

Output:

THE STORY FROM JOHN'S POINT OF VIEW

I needed to get some dough. So I got myself this gun, and I 
went down to the liquor store. I told the shopkeeper that if he didn't let me have the money, then I'd shoot him. So he handed it over. Then I left the store.

THE STORY FROM OWNER'S POINT OF VIEW

I was minding the store. Then a man entered. He threatened me with a gun and demanded all the cash receipts. Well, I didn't want to get hurt, so I gave him the money. Then he escaped from the store.

Story 6. (1) JOHN WANTED SOME MONEY. (2) JOHN GOT A GUN (3) AND WALKED INTO A LIQUOR STORE. (4) JOHN TOLD THE OWNER JOHN WOULD GIVE THE OWNER JOHN'S GUN IF THE OWNER GAVE JOHN TEN DOLLARS.

Output:

THE STORY FROM JOHN'S POINT OF VIEW

I needed to get some dough. So I got myself this gun, and I went down to the liquor store. I told the shopkeeper that I wanted to sell him the gun for ten dollars.

THE STORY FROM OWNER'S POINT OF VIEW

I was minding the store when a man entered. He had a gun, so I thought he was going to rob the store, but he just wanted to sell me the gun for ten dollars.

\section{TALESPIN}

Another task that indicates what computers can do when knowledge is made available to them is the creation of stories.

TALESPIN is a program (Meehan, 1976) that makes up stories by simulating a world, assigning goals to some characters and saying what happens when these goals interact with events in the simulated world. The reader/ user may supply much of the information about the initial state of the world, such as the choice of characters and the relationships between one character and another.

Below are two stories written by TALESPIN. Story 7 is in an interactive mode, where the user may make decisions. Story 8 is told with no user interaction. Uppercase output is from the program, either as part of the story (JOHN BEAR ATE THE HONEY), or as part of the question-answer dialogue (HOW HUNGRY IS IRVING BIRD?). Our answers to these questions are typed when an asterisk (*) appears.

Story 7. **********WELCOME TO TALESPIN $* * * * * * * * *$ CHOOSE ANY OF THE FOLLOWING CHARACTERS FOR THE STORY: (BEAR BEE BOY GIRL FOX CROW ANT HEN LION DOG WOLF MOUSE CAT GOAT CANARY)

*(BEAR BEE BOY CANARY)

IRVING BEE IS AT THE BEEHIVE. SOME HONEY IS AT THE BEEHIVE. IRVING BEE HAS THE HONEY. SAM ADAMS IS AT A HOUSE. WILMA CANARY IS AT A NEST. CHOOSE ANY OF THE FOLLOWING PROPS: (BREADCRUMBS CHEESE BASEBALL)

*NIL

CHOOSE ANY OF THE FOLLOWING MISCELLANEOUS ITEMS: (BERRIES FLOWER RIVER WORM)

*(BERRIES WORM)

SOME BLUBERRIES ARE AT A BUSH. A WORM IS AT A PATCH OF GROUND.

WHO KNOWS ABOUT THE BLUEBERRIES? 1: WILMA CANARY 2: SAM ADAMS 3: IRVING BEE 4: JOHN BEAR *4

JOHN BEAR THINKS THAT THE BLUEBERRIES ARE AT THE BUSH
HOW HUNGRY IS JOHN BEAR? 1: VERY 2: SOMEWHAT 3: NOT VERY 4: NOT AT ALL

$*_{4}$

JOHN BEAR IS NOT VERY HUNGRY.

WHO KNOWS ABOUT THE WORM? 1: WILMA CANARY 2: SAM ADAMS 3: IRVING BEE 4: JOHN BEAR

$* 2$

SAM ADAMS THINKS THAT THE WORM IS AT THE PATCH OF GROUND.

THIS IS A STORY ABOUT ... 1: WILMA CANARY 2: SAM ADAMS 3: IRVING BEE 4: JOHN BEAR

$* 2$

HIS PROBLEM IS THAT HE IS ... 1: HUNGRY 2: THIRSTY 3: HORNY 4: TIRED

$* 1$

SAM ADAMS IS SOMEWHAT HUNGRY. SAM ADAMS WANTS TO GET SOME BERRIES. SAM ADAMS WANTS TO FIND OUT WHERE SOME BERRIES ARE.

DOES SAM ADAMS LIKE WILMA CANARY? 1: A LOT 2: A LITTLE 3: NOT MUCH 4: NOT AT ALL

$* 2$

SAM ADAMS WANTS WILMA CANARY TO TELL SAM ADAMS WHERE SOME BERRIES ARE.

DOES SAM ADAMS FEEL DECEPTIVE TOWARD WILMA CANARY? 1: A LOT 2: A LITTLE 3: NOT MUCH 4: NOT AT ALL

*4

DOES SAM ADAMS FEEL COMPETITIVE TOWARD WILMA CANARY? 1: A LOT 2: A LITTLE 3: NOT MUCH 4: NOT AT ALL

*2

SAM ADAMS DECIDES THAT WILMA CANARY MIGHT WANT SAM ADAMS TO GIVE WILMA CANARY A WORM. SAM ADAMS WANTS TO ASK WILMA CANARY WHETHER WILMA CANARY WILL TELL SAM ADAMS WHERE SOME BERRIES ARE IF SAM ADAMS GIVES WILMA CANARY A WORM. SAM ADAMS WANTS TO GET NEAR WILMA CANARY. SAM ADAMS WALKS FROM THE HOUSE TO THE GROUND BY THE REDWOOD TREE BY GOING THROUGH A VALLEY THROUGH A MEADOW. SAM ADAMS IS AT THE GROUND BY THE REDWOOD TREE. WILMA CANARY THINKS THAT SAM ADAMS IS AT THE GROUND BY THE REDWOOD TREE. SAM ADAMS ASKS WILMA CANARY WHETHER WILMA CANARY WILL TELL SAM ADAMS WHERE SOME BERRIES ARE IF SAM ADAMS GIVES WILMA CANARY A WORM.

DOES WILMA CANARY FEEL DECEPTIVE TOWARD SAM ADAMS? 1: A LOT 2: A LITTLE 3: NOT MUCH 4: NOT AT ALL

*1

WILMA CANARY TELLS SAM ADAMS THAT WILMA CANARY WILL TELL SAM ADAMS WHERE SOME BERRIES ARE. SAM ADAMS THINKS THAT WILMA CANARY WILL TELL SAM ADAMS WHERE SOME BERRIES ARE. SAM ADAMS WANTS TO GET A WORM. SAM ADAMS WANTS TO GET NEAR THE WORM.

IN CREATING A VALLEY, WE CAN MAKE UP A NEW ONE OR USE AN OLD ONE. DO YOU WANT TO USE ANY OF THESE? 1: *VALLEY*0 2: *VALLEY*1 - DECIDE: *YES

PLEASE TYPE AN INTEGER BETWEEN 1 AND 2 *2

SAM ADAMS WALKS FROM THE GROUND BY THE REDWOOD TREE TO THE PATCH OF GROUND BY GOING THROUGH THE MEADOW THROUGH THE VALLEY THROUGH THE MEADOW. WILMA CANARY THINKS THAT SAM ADAMS ISN'T AT THE GROUND BY THE REDWOOD TREE. SAM ADAMS TAKES THE WORM. SAM ADAMS WANTS TO GET NEAR WILMA CANARY. SAM ADAMS WALKS FROM THE PATCH OF GROUND TO THE GROUND 
BY THE REDWOOD TREE BY GOING THROUGH THE MEADOW THROUGH THE VALLEY THROUGH THE MEADOW. WILMA CANARY THINKS THAT SAM ADAMS IS AT THE GROUND BY THE REDWOOD TREE. SAM ADAMS GIVES WILMA CANARY THE WORM. WILMA CANARY THINKS THAT SAM ADAMS GAVE WILMA CANARY THE WORM. WILMA CANARY THINKS THAT WILMA CANARY HAS THE WORM.

HOW HUNGRY IS WILMA CANARY? 1: VERY 2: SOMEWHAT 3: NOT VERY 4: NOT AT ALL *1

WILMA CANARY EATS THE WORM. THE WORM IS GONE. WILMA CANARY IS NOT VERY HUNGRY. WILMA CANARY TELLS SAM ADAMS THAT SAM ADAMS IS NOT AT ALL SMART. SAM ADAMS LIKES WILMA CANARY NOT AT ALL. SAM ADAMS TRUSTS WILMA CANARY NOT AT ALL. SAM ADAMS DECIDES THAT WILMA CANARY MIGHT WANT SAM ADAMS TO GIVE WILMA CANARY SOME CHEESE. SAM ADAMS ASKS WILMA CANARY WHETHER WILMA CANARY WILL TELL SAM ADAMS WHERE SOME BERRIES ARE IF SAM ADAMS GIVES WILMA CANARY SOME CHEESE. WILMA CANARY TELLS SAM ADAMS THAT WILMA CANARY WILL TELL SAM ADAMS WHERE SOME BERRIES ARE. SAM ADAMS WANTS TO GET SOME CHEESE. SAM ADAMS WANTS TO FIND OUT WHERE SOME CHEESE IS.

DOES SAM ADAMS LIKE IRVING BEE? 1: A LOT 2: A LITTLE 3: NOT MUCH 4: NOT AT ALL

*4

DOES SAM ADAMS LIKE JOHN BEAR? 1: A LOT 2: A LITTLE 3: NOT MUCH 4: NOT AT ALL

*4

SAM ADAMS DIDN'T FIND OUT WHERE SOME CHEESE IS. SAM ADAMS DOESN'T GET SOME CHEESE.

DOES SAM ADAMS DOMINATE WILMA CANARY? 1 : A LOT 2: A LITTLE 3. NOT MUCH 4: NOT AT ALL *3

SAM ADAMS STRIKES WILMA CANARY. WILMA CANARY IS NOT AT ALL HEALTHY. WILMA CANARY WON'T TELL SAM ADAMS WHERE SOME BERRIES ARE. SAM ADAMS DIDN'T FIND OUT WHERE SOME BERRIES ARE. SAM ADAMS DOESN'T GET SOME BERRIES. THE END.

Below is Story 8 . It was generated by TALESPIN in a noninteractive mode. That is, TALESPIN itself made all the decisions.

Story 8. ONCE UPON A TIME GEORGE ANT LIVED NEAR A PATCH OF GROUND. THERE WAS A NEST IN AN ASH TREE. WILMA BIRD LIVED IN THE NEST. THERE WAS SOME WATER IN A RIVER. WILMA KNEW THAT THE WATER WAS IN THE RIVER. GEORGE KNEW THAT THE WATER WAS IN THE RIVER. ONE DAY WILMA WAS VERY THIRSTY. WILMA WANTED TO GET NEAR SOME WATER. WILMA FLEW FROM HER NEST ACROSS A MEADOW THROUGH A VALLEY TO THE RIVER. WILMA DRANK THE WATER. WILMA WAS NOT THIRSTY.

GEORGE WAS VERY THIRSTY. GEORGE WANTED TO GET NEAR SOME WATER. GEORGE WALKED FROM HIS PATCH OF GROUND ACROSS THE MEADOW THROUGH THE VALLEY TO A RIVER BANK. GEORGE FELL INTO THE WATER. GEORGE WANTED TO GET NEAR THE VALLEY. GEORGE COULDN'T GET NEAR THE VALLEY. GEORGE WANTED TO GET NEAR THE MEADOW. GEORGF COULDN'T GET NEAR THE MEADOW. WILMA WANTED GEORGE TO GET NEAR THE MEADOW. WILMA WANTED TO GET NEAR GEORGE. WILMA GRABBED GEORGE WITH HER CLAW. WILMA TOOK GEORGE FROM THE RIVER
THROUGH THE VALLEY TO THE MEADOW. GEORGE WAS DEVOTED TO WILMA. GEORGE OWED EVERYTHING TO WILMA. WILMA LET GO OF GEORGE. GEORGE FELL TO THE MEADOW. THE END.

Below are four stories that were generated by TALESPIN that were mistakes. We present them here for two reasons. First, they illustrate the kind of problems that TALESPIN solves in telling its stories. But, more significantly, they indicate why researchers in artificial intelligence use computers. It is very difficult to fully understand and thus to fully specify the complex processes that are part of human intelligence. When we begin to build a model of an intelligent process, we start to discover why what we first hypothesized was incomplete or inaccurate. We can then revise our model on the basis of our failures.

Story 9. HENRY ANT WAS THIRSTY. HE WALKED OVER TO THE RIVER BANK WHERE HIS GOOD FRIEND BILL BIRD WAS SITTING. HENRY SLIPPED AND FELL IN THE RIVER. HE WAS UNABLE TO CALL FOR HELP. HE DROWNED.

Story 10. HENRY ANT WAS THIRSTY. HE WALKED OVER TO THE RIVER BANK WHERE HIS GOOD FRIEND BILL BIRD WAS SITTING. HENRY SLIPPED AND FELL IN THE RIVER. GRAVITY DROWNED.

Story 11. ONCE UPON A TIME THERE WAS A DISHONEST FOX AND A VAIN CROW. ONE DAY THE CROW WAS SITTING IN HIS TREE, HOLDING A PIECE OF CHEESE IN HIS MOUTH. HE NOTICED THAT HE WAS HOLDING THE PIECE OF CHEESE. HE BECAME HUNGRY, AND SWALLOWED THE CHEESE. THE FOX WALKED OVER TO THE CROW. THE END.

Story 12. JOE BEAR WAS HUNGRY. HE ASKED IRVING BIRD WHERE SOME HONEY WAS. IRVING REFUSED TO TELL HIM, SO JOE OFFERED TO BRING HIM A WORM IF HE'D TELL HIM WHERE SOME HONEY WAS. IRVING AGREED. BUT JOE DIDN'T KNOW WHERE ANY WORMS WERE, SO HE ASKED IRVING, WHO REFUSED TO SAY. SO JOE OFFERED TO BRING HIM A WORM IF HE'D TELL HIM WHERE A WORM WAS. IRVING AGREED. BUT JOE DIDN'T KNOW WHERE ANY WORMS WERE, SO HE ASKED IRVING, WHO REFUSED TO SAY. SO JOE OFFERED TO BRING HIM A WORM IF HE'D TELL HIM WHERE A WORM WAS ....

\section{POLITICS}

Over the years, psychology has learned things from AI and AI has learned things from psychology. One of the best examples of this mutual sharing of ideas comes from the joint effort of Robert Abelson and myself on the problem of modeling an ideology. Some years ago, Abelson (1966) constructed a program that was intended to be a model of an ideological cold warrior. It did not work very well, largely because of the lack of understanding at the time of how to process natural language. With the advent of scripts as used by SAM, we set out to look at the problem again. This resulted in the POLITICS program (Carbonell, in press), whose output is shown below. The input to POLITICS is a sentence that one might find in a headline of a news story. POLITICS is then asked questions about what 
it believes underlies the motivations of the actors. The answers presented here are in accord with one possible political philosophy. POLITICS has a number of possible philosophies that can be input to it.

INPUT TEXT: Russia massed troops on the Czech border. Why did Russia do this? BECAUSE RUSSIA THOUGHT THAT IT COULD TAKE CONTROL OF CZECHOSLOVAKIA BY SENDING TROOPS. What will Russia do next?

RUSSIA MAY ORDER ITS TROOPS INTO CZECHO-

SLOVAKIA.

What can the United States do?

THE UNITED STATES CAN DO NOTHING, IT CAN

INTERVENE MILITARILY IN CZECHOSLOVAKIA

BY SENDING TROOPS, OR IT CAN INTERVENE

DIPLOMATICALLY BY TALKING TO RUSSIA ABOUT

CZECHOSLOVAKIA.

What should the United States do?

THE UNITED STATES SHOULD INTERVENE MILITARILY.

INPUT TEXT: Russia sent massive arms shipments to the

MPLA in Angola.

Why did Russia do this?

RUSSIA WANTS TO CONTROL ANGOLA THROUGH

THE MPLA.

What will the MPLA use the arms shipments for?

THE MPLA WILL ATTEMPT TO TAKE OVER ANGOLA

USING THE ARMS SHIPMENTS.

What will the other factions in Angola do?

THE OTHER FACTIONS WILL ASK SOME OTHER

COUNTRY FOR ARMS.

Which country?

THE UNITED STATES.

Should the US do anything about it?

YES, THE US SHOULD SEND ARMS TO THE OTHER

FACTIONS IN ANGOLA.

*(INTERPRET US-CONSERVATIVE) INPUT TEXT: The United States Congress voted to fund the Trident submarine project.

What did the US Congress do this for?

THE UNITED STATES CONGRESS WANTS THE UNITED

STATES ARMED FORCES TO BE STRONGER.

Why should the US be stronger?

THE UNITED STATES ARMED FORCES SHOULD BE

STRONG TO STOP COMMUNIST EXPANSION.

What should the US do if Russia builds nuclear submarines? THE UNITED STATES SHOULD BUILD MORE SUBMARINES.

*(INTERPRET US-LIBERAL) INPUT TEXT: The United States Congress voted to fund the Trident submarine project.

What did the US Congress do this for?

THE UNITED STATES CONGRESS FEARED FALLING BEHIND IN THE ARMS RACE.
What will Russia do next?

RUSSIA WILL PROBABLY BUILD MORE WEAPONS.

What should the US do if Russia builds submarines?

THE UNITED STATES SHOULD NEGOTIATE WITH RUSSIA TO STOP THE ARMS RACE.

\section{CONCLUSION}

Has AI solved all of psychology's problems? I think not. On the other hand, it does provide food for thought. The conclusion from all this seems rather simple. Psychologists should pay attention to AI because AI workers are coming up with ideas that provide theories for psychologists to test. Furthermore, if the idea that a computer program offers a good facility by which one can build and test complex models of processes becomes more acceptable in psychology, we may hope to begin to see psychological theories of a grander scope than we are now seeing.

\section{REFERENCE NOTES}

1. Minsky, M. A framework for representing knowledge (A. I. Memo 306). Cambridge, Mass: MIT, A. I. Laboratory, 1974.

2. DeJong, G. F. Skimming newspaper stories by computer (Research Report 104). New Haven, Conn: Yale University, 1977.

\section{REFERENCES}

Abelson, R. P. Heuristic processes in the human application of verbal structures in new situations. XVIII International Congress on Psychology, Symposium 25, 1966.

Carbonell, J. G. Automated ideological reasoning. Cognitive Science, in press.

Cullingrord, R. E. Organizing world knowledge for story understanding by computer. Unpublished doctoral dissertation, Yale University, 1977.

Lehnert, W. G. Process of question answering. Unpublished doctoral dissertation, Yale University, 1977.

Meehan, J. R. The metanovel: Writing stories by computer. Unpublished doctoral dissertation, Yale University, 1976.

RIesbeck, C. K. Conceptual analysis. In R. C. Schank (Ed.), Conceptual information processing. Amsterdam: North Holland Publishing Company, 1975.

SCHANK, R. C. Conceptual information processing. Amsterdam: North Holland Publishing Company, 1975.

Schank, R. C., \& Abelson, R. P. Scripts, plans, goals and understanding. Hillsdale: N.J: 1977.

WiLENSKY, R. Using plans to understand natural language. Proceedings of the Annual Conference of the ACM. Houston, Tex: 1976. 